\title{
HEALTH LITERATE CHILD: TRANSFORMING TEACHING IN SCHOOL HEALTH EDUCATION
}

\author{
Zanda Rubene \\ Inese Stars \\ Liva Goba \\ University of Latvia, Latvia
}

\begin{abstract}
Health literacy and health education are reciprocally connected concepts in modern scientific discourse. Educational institutions, especially schools, are defined as one of the main arenas for the development and promotion of the child's health literacy. Thus, health literacy, conceptualized as the outcome of school learning, becomes the aim of school health education. As concept of health literacy becomes more complicated its attainment requires more advanced and specific teaching methods, which, in its turn, demands transformations in teacher education and teachers' professional development as well as to perceive the child as an active participant in the teaching/learning process. Good health literacy leads to the child empowerment.
\end{abstract}

Keywords: child's agency, child empowerment, health literacy, school health education, transforming teaching.

\section{Introduction}

Education and health are closely linked - this is a well-known and proved association. However, understanding of the causal relationships between education and health are ambiguous due to its reciprocal nature, namely, good health is a prerequisite for better educational achievements and learning outcomes, and vice versa - education and educational setting are important factors for good health and healthy lifestyle (Eide \& Showalter, 2011). Education and literacy is one of the major determinants of health and both together they are essential for developing health literacy (Kickbusch, 2001).

Health literacy is a challenging concept and is mentioned as a heterogeneous phenomenon in scientific literature because of difficulties in conceptualization (Martensson et al., 2012). World Health organization defines health literacy as the cognitive and social skills that determine the motivation and ability of individuals to gain access to, understand and use information in ways which promote and maintain good health (WHO, 1998).

Health literacy is an outcome that should be taught, trained and reached by formal and/or informal activities on the individual as well as the social level. Developing of comprehensive health literacy, to a considerable degree, is a task of health promotion and health education (Leger, 2001). School health education programs can increase children functional health knowledge, as well as develop skills and competencies that are critical for forming attitudes and motivation that 
will determine health-related behaviour and implementation of healthy lifestyle. Also, health literacy is closely linked to the notion of "empowerment" (Nutbeam, 2000). Used in such a context the notion "empowerment" denotes the ability of the individual to recognize the social character of health, to understand the factors influencing health and to change them for the purpose of health promotion. The individual, also the child, becomes an active participant in the formation of personal as well as the community health conditions.

Health literacy empowers the person - but in order to achieve it appropriate health education is needed, starting from purposeful policy till adequate teaching/learning methods, materials, conditions and the most important teachers trained in health promotion and health education in school settings (Jourdan, 2011). School health education in the $21^{\text {st }}$ century needs to be revised in order to meet all three levels of health literacy - functional, interactive and critical (Nutbeam, 2000) which leads to a health literate child and his/her empowerment.

The main purpose of the research is to substantiate the necessity of transforming teaching in order to ensure conditions and opportunities for children to become more active participants in the learning process of health literacy. The necessary aspects of training for teachers to enable them to integrate the notion of active health literacy in their teaching practice and to deal with health issues within school health education will also be outlined.

The paper is written using the theoretical research method - in depth analysis of scientific literature. The research question of the study is: what are the anticipated transformations in teaching at school as well as the transformations needed in teacher training and professional development in order to achieve the child health literacy as an educational outcome?

\section{Results and discussion Vulnerable Child versus Child as an Agent}

The image of the child as a vulnerable creature as well as the theory of childhood as the happiest and most care-free period of human life is a typical anthropological tradition characteristic of classical pedagogical thought (Hummelbach \& Schröer, 2014).

This ideological approach substantiates the understanding about the child as a vulnerable being who needs the adults' care and protectionism and which grounds the hierarchic pedagogical relations between the adults and children.

Biologically, the stage of childhood lasts from birth until the beginning of puberty. The concept 'child' in the framework of legislation borders on the concept of majority or the age when human reaches the legal status of an adult. In the childhood studies special attention is paid to this age category in relation to the structuring of the child's everyday experience in regard to socialization (Bühler-Niederberger, 2011). Similarly, the understanding about the physical 
body as the indicator of the biological age, in this case - the childhood, is explained in the research. The development of human body is biologically determined; however, the assessment of the body depends crucially on the social norms and the society's expectations how to behave and how to look (Harper \& Laws, 1995). To be more precise, the attitude towards the child's body in the particular society is socially structured.

The child's body in the context of the childhood studies is allotted to a dual meaning - it represents the lack of the adult competence and sentimentalises the abilities and traits inherent in the child (James, 2004). The child's body is treated as vulnerable and imperfect, thus the child is not able to act independently. The notions "obedience" and "innocence" characterize the 'Vulnerable Child' concept. Child is perceived as an incompetent, socially unformed being that needs protection and care (Bühler-Niederberger, 2011). The views on upbringing based on this image of the child, on the one hand, idealizes the childhood emphasizing it as a happy and safe period in the human life. On the other hand, the child is perceived as the potential victim of the social processes who needs to be cared for even if he does not want it because the child simply does not understand what is needed for him. This also serves as a reason for the child's protection from the knowledge and social action areas that "do not pertain" to the child because the child is simply "too young for all this". Traditionally, the information that is harmful to the child and that damages his happy childhood, for instance, is connected with the adults' relations in the family and sexuality as well as the death, diseases. (Parsons, 1951) The innocent and vulnerable child should reach competence and maturity through purposeful adult guidance. If the child complies with the understanding of values and norms dictated by the adults he will turn into an adult and will correspond to the understanding of an equal member of the society.

Thus the traditional view of the classical pedagogical thought on the child as a vulnerable being substantiates the opinion that the child himself is not competent in constructing his/her own health literacy. The child's activities in this area can threaten the social order created by adults and only the adult care and protection are the tools for reaching maturity in this area.

A new understanding emerged in the discourse of social sciences in the $90^{\mathrm{s}}$ of the $20^{\text {th }}$ century- the child as an actor which essentially transforms the classical view on the child promoting the understanding of equal cooperation between the child and adults in pedagogy. It emphasizes that a child as well as the adult is an active and competent being who himself is the producer of one's own socialization process (James \& Prout, 1997), yet without producing the idea about permissiveness, the disappearance of norms and regulations in the child's life. The concept of agency considerably increases the understanding of the child as a value promoting the formation of a child-centred society.

The concept of agency in the discourse of social sciences entails the individual's ability to act independently and to make a free choice. Agency 
involves the individual's abilityto lead the life in the desired direction, the readiness to take the responsibility and challenges as well as to set meaningful aims for oneself (Bela \& Tīsenkopfs, 2006).

The topicality of the image of thechild as an actor can be explained with the liberalization trends in upbringing where the egalitarian family model develops as an opposite to the patriarchal family model (Jansone-Ratinika, 2013). It is characterized by mutual respect among the family members as well as the relations directed not towards the obedience but towards the independence and cooperation. Consequently, thechild as an actor is perceived as a human being who is aware of his/her needs and rights and is a competent and independent constructor of his/her identity.

The phenomenon of the child as an actor also drives the learner-centred study process at school focussing on the child's individual needs not on the teacher's desires or the curriculum requirements.

The contradiction between the Vulnerable Child and Child as an Agent initiates the discussion about the development and promotion of the child health literacy in the health education.

\section{Health literate child and empowerment}

The heading "Health literate child" raises at least two provocative questions: 1) Is it possible to draw a profile of a "health literate" child or more precisely - what should the child know and be able to do in order to be health literate? and 2) How is health literacy related to child empowerment?

In theoretical literature, the concept ,health literacy" mainly is attributed to adults, not the children and, thereby, creates conceptual difficulties in fullfledged application of this notion in the children population. In order to ensure the methodological correctness, child health literacy should be conceptualized, developed and measured in close relationship with the child development stages (Borzekowski, 2009). There is also a shift from the notion of vulnerable child to a more active child in health promotion and health education. The child is given the possibility to become a participant in the promotion of one's health and the child's self-defined health needs are recognized as legitimate (Kalnins et al., 1992).

According to the conceptual models of health literacy, a health literate child must be able to develop functional, interactive and critical health literacy (Nutbeam, 2000), as well as citizenship (Paakkari \& Paakkari, 2012), media literacy and media competencies (Manganello, 2008). Functional health literacy ensures that the child is able to read, understand, and act on basic health information and has factual knowledge about different health topics (nutrition, physical activity, safety, sexuality, hygiene, drugs etc.). Interactive health literacy is responsible for the development of more advanced and specific cognitive and social skills (communication, problem solving, food preparation 
etc.) which, in their turn, encourage child's independency. Critical health literacy places health in a broader context, i.e., beyond an individual. It addresses societal and community level of health and recognizes social determinants of health. Critical health literacy leads to the child empowerment (St. Leger, 2001). Citizenship as a criterion of health literacy means that children should be taught to become responsible citizens, acting in an ethically responsible way (Paakkari \& Paakkari, 2012) regarding health issues. Media literacy in the context of health literacy is defined as the ability to critically evaluate media messages (Manganello, 2008).

Achievement of a health literate child is a challenging purpose and it is the responsibility of many social institutions: family, education, health care, mass media, religion etc. There is a need to educate and train children on all levels of health literacy - starting from basic health knowledge and functional skills (reading, writing, numeracy etc.) up to empowerment. Health literacy will help children to make more informed and healthier choices and understand health as a social and dynamic issue influenced by many environmental factors. Health education gradually will increase children's control over their health, their ability to participate in disease prevention and health promotion, to seek out information and to take responsibility about their own as well as the health of the community in which they live.

\section{School health education for a health literate child}

Schools are seen as having a key role in health education, which provides people with opportunities to acquire knowledge, skills and competencies, attitudes and motivation required for making healthy decisions, achieving health literacy, adopting health-enhancing and reducing health risk behaviours, and promoting a community health (Tones \& Tolford, 1994). School as one of the most efficient systems for reaching children and youth is regarded an essential setting for health education and health literacy development (Hagquist \& Starrin, 1997). However, health education in schools is a complicated educational issue. It must be as comprehensive as health concept itself and multidisciplinary approach is necessary for an effective teaching process (Jourdan, 2011).

Historically, health education in schools tended to be organized as informational activities within the classroom based on a topic approach, which meant working fragmentary on different health issues such as smoking, alcohol use, physical activity, nutrition, reproductive health, safety, mental health etc. (Jourdan, 2011). A child in such conditions is the receiver of the information more passive than active. Its participation in health education process is limited. Such approach emphasizes the dissemination of factual knowledge on different local health issues but does not form the view about health as a comprehensive 
social phenomenon. Namely, no possibility is given to conceive a broader context of the health.

In order to reach health literacy as the learning outcome (Paakkari \& Paakkari, 2012), the school environment and school culture should create conditions appropriate for this (Hagquist \& Starrin, 1997); especially, it concerns the development of critical health literacy. This necessity challenges the traditional health education model characterized by the "top-down" approach and a narrow contextual framework, and demand transformations in the pedagogical approach. The alternative to the traditional model of school health education is the empowerment model, which offers the "bottom-up" approach and a wide contextual framework and is more oriented on the child as an equal participant, who is able to participate in the identification of one's health needs and in its improvement. The child in this model becomes an involved partner in the health education process (Hagquist \& Starrin, 1997).

\section{Perspectives of Transforming Teaching}

The teacher is a significant actor in the implementation of the empowerment model of health education; however not all teachers are equally supported and equipped for this task. From an organizational culture perspective the teacher is situated in the specific context of the school culture with its historical development, traditions and values, communities and subcultures, social networks and its specific way of leadership as well as internally and externally generated rules and regulations. In fact, everything happening in the culture as a dynamic organizational system of the society, according to the culture model of E.H. Schein (2010), is guided by deeper cultural assumptions about the reality and truth that are largely implicit. The improvement of pedagogical work at school requires not only reviewing the practice of work but also re-examination of basic underlying assumptions about teaching and learning. Respectively, the assumptions about health, healthy lifestyle and school health education should be challenged to transform the existent practice of health literacy teaching.

The school culture is heterogeneous as it is formed and being constantly reshaped by individuals with their own belief systems and life experiences. These differences are expressed also in the understanding of the health concept and health literacy in practice. Cultural change processes are difficult to control as they involve unpredictable aspects; however, they may be influenced and managed to a considerable degree (Shein, 2010; Virkkunen \& Newnham, 2013). It demands a high level of competences and skills to guide the processes of cultural change and it also requires the arousal of transformative agency of all the parties involved. One of the methods for such a change management to be examined is Change Laboratory that is based on the theory of expansive learning and developmental work research. It is aimed at the collective dimension of 
learning and analyses the work activity as a complex, collective, object-oriented, artefact-mediated system, rooted in the community and shaped by its rules and division of labour (Virkkunen \& Newnham, 2013; Engeström, 2009).

However, the trouble with most educational reforms is their focus on the visible manifestations of culture and the normative framework that are easier to measure, rather than the improvement of pedagogic culture itself, which requires transformations of the underlying assumptions about teaching and learning. Instead, in the legal framework the teachers are treated as mere executors of ready-made instructions rather than capacitated actors and therefore are deprived of agency. Namely, the maintenance of and changes to the structure are put before agency building. Nevertheless, though in the educational reform movements a short-term oriented business capital approach still dominates (promoting competition and accelerating business return through lowering spending on human resources), the idea of professional capital becomes more popular; it recognizes the need to make long-term investments in human capital (including education and professional development) that contributes to the whole society (Hargreaves \& Fullan, 2012; Sahlberg, 2011). Hence, the notion of equity is acknowledged as well as the bottom-up change initiatives and lifelong learning.

The understanding of health literacy as stated above is a challenge to the traditional understanding of schooling and education. We must note that in order for changes to take place in the underlying assumptions about health literacy, a more involving, in-depth learning experience must be fostered for the teachers. The transformative learning theory by Jack Mezirow (1991) explicates such learning: in order to transform the meaning perspectives (perceptual filters or frames of reference that define how the experience is being interpreted) the main mechanism is critical reflection and examination of assumptions about the process, premises or outcome of the phenomenon in question (Mezirow, 1991). Thus, part of the teacher's everyday practice should provide the possibility and should facilitate the reflection about the pedagogical practice and moreover collaboratively examine and model its further development instead of passively taking on external instructions. The reflection of educators should be aimed not only at the pedagogical means to foster health literacy, but also on the concept of health literacy itself and their own actual experience of handling health issues and practicing healthy habits.

The ultimate object of teachers' work undoubtedly is the child and his meaningful learning (Engeström et al., 2002). With that in mind, some basic aspects on transforming both the way teachers teach and their learning behind it as a reciprocal process has been briefly outlined (Table 1). 
Table 1. The outline of transforming teaching in health education

The TEACHING

FROM school encapsulation and isolated FROM fragmentary teacher professional teacher efforts TO holistic approach in public development TO organizational culture health context

FROM poligraph ic learning TO multi-modal FROM teacher centred learning TO child and blended learning incorporating the centred teaching and learning, the interaction multimedia use which is brought closer to the with the child child's experience

FROM passive knowledge transmission and FROM passive executor of external standardization TO learning by doing and instructions TO capacitated/ competent agent practice of active citizenship and collaborator in solving health-related issues

FROM independent teaching and learning TO FROM professional isolation TO learning interdependent study process and the communities and networks understanding of partnership

FROM fostering of impersonal and FROM isolated and remote teacher training formalistic learning TO personally sessions TO life-long workplace learning and meaningful and experience-based learning practice of health literacy

In order for these outlined transformations to take place, it must be noted that, firstly, no change will take place without investment in the professional capital of teachers. A system of support for pedagogical professional development and experimentation must be created and continuously enhanced. Secondly, the action must be directed at the development of school culture that values collaboration, open communication and reciprocal learning within the school as well as institutions and agencies outside of it. Thirdly, a system-wide action ought to be directed at decreasing standardization including reshaping the system of accountability from a mass-standardised and quantitative to a more qualitatively driven and learner-centred. Finally, when those support mechanisms are in place the question arises how to foster teacher transformative agency in order to reshape the education system from within (bottom-up) so that the developmental initiative would be handed over to the executors of school health education policies that are closest to the child - the educators.

\section{Conclusions}

1. The liberalization trends in upbringing in a child-centred society in the modern scientific discourse promote the discussion about the child as an actor in the context of health education.

2. Nowadays as the concept of health literacy becomes more complicated and its content more elaborated, health education should ensure the attainment of all levels of health literacy. 
3. A well developed health literacy leads to child empowerment. However, child health literacy must be conceptualized as an issuein its own right and not as a derivation of adult health literacy.

4. In order to implement the school health education that does not restrict and suppress the child but encourages and gives the ability to act, the school should create a supportive environment in all aspects. School culture should be taken into account as the specific context for implementing the holistic approach to health literacy in school.

5. Teachers' (and other actors') action in the implementation of health education is most directly influenced by underlying assumptions about health, child health literacy and school health education that are present in the school. In order for the transformations in teaching to appear these assumptions must be critically re-examined by means of critical reflection and collaborative change efforts rather than by top-down instructions.

6. To transform teaching of health literacy, transformative and in-depth learning efforts of teachers must be fostered in line with continuous workplace learning, collaboration, practice of health literacy and active citizenship. The child must be the ultimate object of any organizational change efforts in school.

\section{References}

$7^{\text {th }}$ Global Conference on Health Promotion: Track Themes: Health Literacy and Health Behaviour. Retrieved from http://www.who.int/healthpromotion/conferences/ $7 \mathrm{gchp} / \mathrm{track} 2 / \mathrm{en} /$

Bela, B., Tīsenkopfs T. (2006). Dzīves kvalitāte Latvijā. Rīga: Zinātne.

Borzekowski, D. L. G. (2009). Considering Children and Health Literacy: A Theoretical Approach. Pediatrics, 124(3), 282-288.

Bühler-Niederberger D. (2011). Lebensphase Kindheit. Theoretische Ansätze, Akteure und Handlungsräume. Weinheim, Basel: Juventa.

Eide, E. R., Showalter, M. H. (2011). Estimating the Relation Between Health and Education: What Do We Know and What Do We Need to Know? Economics of Education Review, 30(5), 778-791.

Engeström, Y. (2009). Expansive learning: Toward an Activity-Theoretical Reconceptualization. In: Illeris, K. (Eds.) Contemporary Theories of Learning: Learning Theorists-in Their Own Words (pp. 53-73). New York: Routledge.

Engeström, Y., Engeström, R. \& Suntio, A. (2002). Can a School Community Learn to Master Its Own Future? An Activity-Theoretical Study of Expansive Learning Among Middle School Teachers. In: Learning for Life in the $21^{\text {st }}$ Century: Sociocultural Perspectives on the Future of Education (pp. 211-224). Oxford: Blackwell.

Hagquist, C., Starrin, B. (1997). Health Education in Schools - From Information to Empowerment Models. Health Promotion International, 12(3), 225-232.

Hargreaves, A., Fullan, M. (2012). Professional Capital: Transforming Teaching in Every School. New York: Teachers College Press.

Harper, S., Laws, G. (1995). Rethinking the Geography of Aging. Journal Progress in Human Geography, 19 (2), 199-221. 


\section{SOCIETY. INTEGRATION. EDUCATION. Volume I}

Hummelbach, N., Schröer, W. (2014). Die transnacionale Kindheit. In: Kindgeiten in der Moderne. Eine Geschichte der Sorge. Frankfurt, New York: Campus, pp. 492-509.

James, A. (2004). Understanding Childhood from an Interdisciplinary Perspective: Problems and Potentials. In: Pufall, P., Unsworth, R. (Eds.) Rethinking Childhood (pp. 25-38). New Brunswick, NJ: Rutgers University Press.

James, A., Prout, A. (1997). Constructing and Reconstructing Childhood: Contemporary issues in the sociological study of childhood. London: RoutledgeFalmer.

Jansone-Ratinika, N. (2013). Tēva pedagoǵiskā kompetence mūsdienu gimenē. Disertācija pedagoğijā. Rīga: LU.

Jourdan, J. (2011). Health Education in Schools. The Challenge of Teacher Training. SaintDenis: Inpes, coll. Santé en action. Retrieved from

http://www.inpes.sante.fr/CFESBases/catalogue/pdf/1380.pdf

Kalnins, I., Mcqueen, V. D., Backett, C. K., Curtice L., CurrieE. C. (1992). Children, Empowerment and Health Promotion: Some New Directions in Research and Practice. Health Promotion International,7 (1), 53-59.

Kickbusch, I. (2001). Health Literacy: Addressing the Health and Education Divide. Health Promotion International, 16(3), 289-97.

Leger, St. L. (2001). Schools, Health Literacy and Public Health: Possibilities and Challenges. Health Promotion International, 16(2), 197-205.

Manganello, J. A. (2008). Health Literacy and Adolescents: a Framework and Agenda for Future Research. Health Education Research, 23(5), 840-7.

Mårtensson, L., Hensing, G. (2012). Health literacy - a Heterogeneous Phenomenon: a Literature Review. Scandinavian Journal of Caring Sciences, 26(1), 151-60.

Mezirow, J. (1991). Transformative Dimensions of Adult Learning. San Francisco: JosseyBass.

Nutbeam, D. (2000). Health Literacy as a Public Health Goal: a Challenge for Contemporary Health Education and Communication Strategies into the $21^{\text {st }}$ Century. Health Promotion International, 15(3), 259-267.

Paakkari, L., Paakkari, O. (2012). Health Literacy as a Learning Outcome in Schools. Health Education, 112 (2), 133-152.

Parsons, T. (1951). The Social System. New York: Free Press.

Sahlberg, P. (2011). Finnish lessons. What Can the World Learn from Educational Change in Finland? New York: Teachers College Press.

Schein, E. H. (2010). Organizational Culture and Leadership. Fourth edition. San Francisco: Jossey-Bass.

Tones, K., Tolford, S. (1994). Health Education: Effectiveness and Efficiency. London: Chapman and Hall.

Virkkunen, J., Newnham, D. S. (2013). The Change Laboratory: A Tool for Collaborative Development of Work and Education. Rotterdam: Sense Publishers. 